\title{
Climate change and adolescents in South Africa: The role of youth activism and the health sector in safeguarding adolescents' health and education
}

Today's youth will inherit a world made hazardous by greenhouse gases. As a general rule, those chiefly responsible for emitting these gases will be spared the full brunt of their effects. Age has become a clear fault line of this phenomenon: while today's adults will experience some impacts of these emissions, adolescents and future generations will face their full force in time.

The voices of young people are seldom included in discourses around health policy. Recently, however, adolescents have begun to assert their position within the 'climate crisis. ${ }^{\left[{ }^{[1]}\right.}$ Initiatives like staging a school strike every Friday (\#ClimateStrike), forming 'Extinction Rebellion' protests and blocking public sites like the London Tower Bridge have generated considerable momentum. ${ }^{[2]}$ In several countries, adolescents are also employing litigation as a means of holding their governments and the private sector to account, a strategy that may have some merit in South Africa (SA) (see box 'Youthled litigation against the South African government and private sector: A turning point for securing the future health of children?'). ${ }^{[3]}$

Not all adolescents are equally empowered to take up these challenges, however. There are major gaps in knowledge about climate change among adolescents in many low- and middle-income countries, including $\mathrm{SA},{ }^{[4,5]}$ and climate activism is nascent in these settings. ${ }^{[6]}$

In SA there are around 10 million adolescents (10 - 19 years), who make up about $20 \%$ of the country's population. ${ }^{[7]}$ They already face a gamut of challenges, ranging from HIV infection, sexual and physical violence, teenage pregnancy and substance use to poverty, inequality and gangsterism. Additionally, many schools are unsafe, with overcrowded classrooms and high levels of environmental toxins, and educational outcomes are poor. ${ }^{[8,9]}$

Overall, the effects of climate change on adolescents, and the effects of heat exposure in particular, are underappreciated. In this commentary we present evidence of how adolescents are already being affected by climate change and how these effects will deepen in the near future (Fig. 1). Many health practitioners have little insight into the impacts of heat on outcomes such as

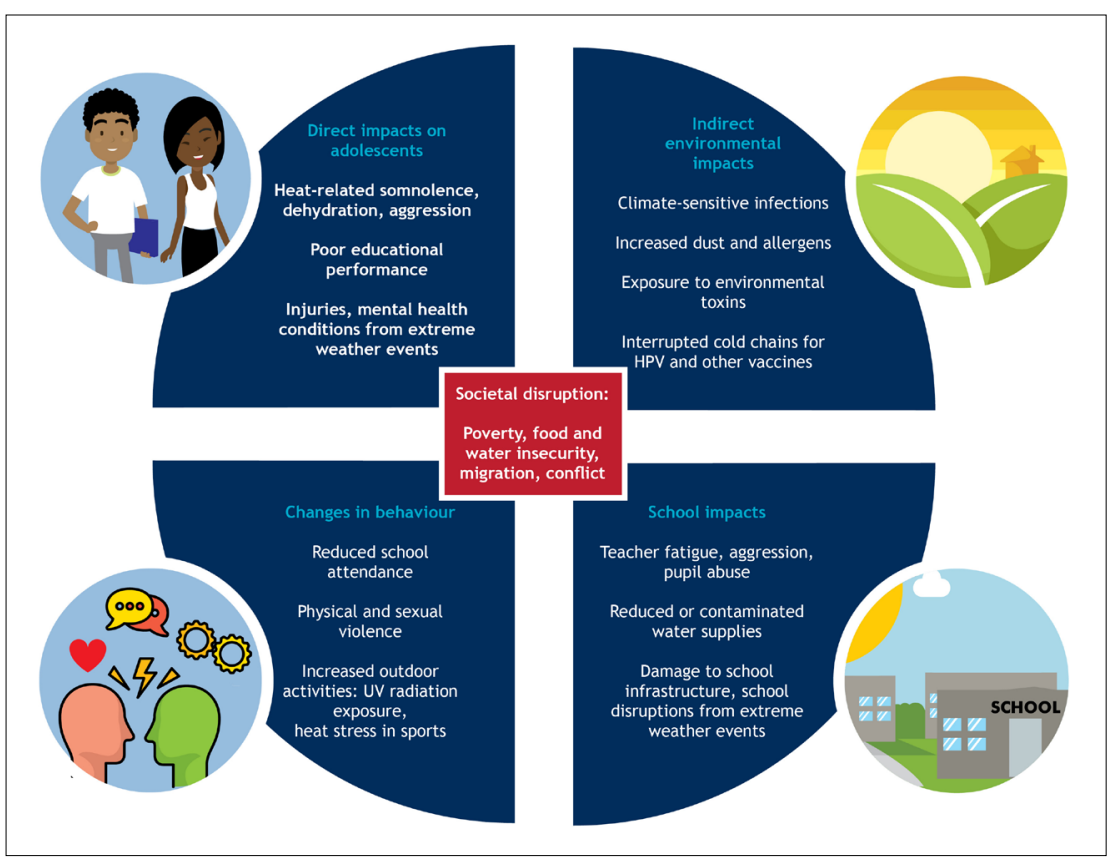

Fig. 1. Impacts of climate change on health and educational performance of adolescents.

comfort while at school and cognition more generally, ${ }^{[10]}$ education attainment and violence. Even if aware of these issues, they are likely to regard them as being outside the remit of the health sector. Equally, the education sector may not see these matters as health related. We aim to demonstrate the centrality of the health sector to countering climate change impacts on adolescents in SA.

\section{Impacts of climate change on adolescents' health}

Changes in climate affect children and adolescents in unique ways, given their dynamic biological, psychosocial and cognitive development. ${ }^{[11]}$ Adolescents and adults have similar physiological thermoregulatory mechanisms, ${ }^{[12]}$ but adolescents may lag in behavioural thermoregulation, for example owing to inadequate fluid intake. ${ }^{[13]}$ Compared with boys, the effects on girls may be greater, given that they have higher rates of obesity (which compromises thermoregulation), and of mental health conditions and mortality during extreme weather events. ${ }^{[14]}$ Similarly, subgroups of adolescents with limited physical or monetary resources to counter the impacts of climate change, such as those living in extreme poverty or with disabilities, may also be at increased risk.

Generally children spend more time outdoors than adults, raising their exposure to solar ultraviolet radiation and their risks for exertional heat injuries in sports. Additionally, about $20 \%$ of children aged $7-17$ in SA are engaged in some form of economic activity, producing goods for the 'market' or for their own household. ${ }^{[15]}$ About 17\% of these children report working in conditions characterised by 'extreme temperatures and humidity', which equates to around 400000 children at considerable risk for dehydration and heat stress during heatwaves. ${ }^{[15]}$

Changes in water quality and availability are principal manifestations of climate change, and have implications for adolescent health. Droughts may threaten water security in schools in SA, where water is often drawn from boreholes or even rivers. Floods, however, can also contaminate water with infectious agents and toxins. Further, safe water for sanitation and hygiene is especially important in SA, since around 30\% of schools use pit latrines or have no toilet at all. ${ }^{[16]}$ Most water- and foodborne infections, particularly those of bacterial aetiology, are heat sensitive, of particular concern among adolescents given that close contact in 


\section{Youth-led litigation against the South African government and private sector: A turning point for securing the future health of children?}

In recent years, youth across the world have employed litigation as a means of asserting their rights in the climate crisis. ${ }^{[1]}$ In The Netherlands in 2018, for example, the Court of Appeal in the Hague recognised the rights of children to demand that the government reduce national emissions by a specified amount, and also that they have a 'duty of care ... [to future generations] ... to prevent hazardous climate change. ${ }^{2]}$ In the same year, in a case brought by 25 youth in Colombia, the Supreme Court ordered the Colombian government to take steps to reduce climate change and deforestation, and also ruled that the Colombian Amazon rainforest is 'a subject of rights' that is entitled to 'protection, conservation, maintenance and restoration'. And in 2014, 21 youths in the USA initiated a case alleging that the government's inaction on addressing climate change violated their constitutional rights to life, liberty and property. After 4 years of delays, the US Supreme Court ruled that the case may proceed, ${ }^{[3]}$ despite the country's Department of Justice holding that 'there is no right to a climate system capable of sustaining human life, among other arguments. ${ }^{[4]}$

While overall climate change litigation has met with mixed success, a case brought by youth in South Africa (SA) may have merit. The country has one of the most progressive constitutions in the world, and, unlike many others, it expressly sets out the right to a healthy environment. Specifically, section 24 of the Constitution could be relied on in its entirety to argue for stronger climate change mitigation measures. It states that:

'Everyone has the right:

(a) to an environment that is not harmful to their health or wellbeing; and

(b) to have the environment protected, for the benefit of present and future generations, through reasonable legislative and other measures that -

(i) prevent pollution and ecological degradation;

(ii) promote conservation; and

(iii) secure ecologically sustainable development and use of natural resources while promoting justifiable economic and social development.

Additionally, section 28 sets out the core rights of children and could be used to support arguments based on section 24 . Section 28 provides that every child has the right 'to basic nutrition, shelter, basic health care services and social services', each of which will be progressively eroded by climate change. The section also directs that 'A child's best interests are of paramount importance in every matter concerning the child. It is indisputable that a healthy environment and stable climate is in the best interests of a child, and the SA government therefore has a duty to respect, protect, promote and fulfil these rights.

Key questions underpinning a Constitutional Court challenge include whether the country is meeting its commitments to international climate change treaties, has a reasonable climate change policy in place, and is on track towards a low carbon economy. Claims have already been made against the government that the constitutional right of people in Mpumalanga to clean air is being infringed upon by industry in the province. ${ }^{[5]}$ Could this litigation provide the foundation for future court cases where, for example, young South Africans impel the government to remove barriers to renewable energy production or to use taxation and add warning labels as a means of curbing the intake of ruminant meat? (Fig. 2).

A case might also be made for imposing civil liability to private sector entities deemed responsible for greenhouse gas emissions, and impelling these companies to set caps on emissions. ${ }^{[1]}$ Legal strategies in such cases could draw on precedents in the asbestos class action suit in SA and tobacco litigation elsewhere. An analagous case - albeit unsuccessful - was brought by Mississippi residents against oil and gas companies for their contribution to the intensity and magnitude of Hurricane Katrina. In this and similar cases, the court judgments expressed concerns about questions of 'allocation of fault - and cost - of global warming. ${ }^{[1]}$

SA has some of the largest coal-producing companies in the world, companies whose activities, one could plausibly argue, pose major threats to the health of current and future children in the country. Claims may also be made against such companies for non-disclosure of climate-related health risks from their activities, which would include taking reasonable steps to quantify the disease burden that can be attributed to their emissions. Costs of current and future disease burdens could then be explicitly taken into account when decisions are made about whether to invest in brown or green energy sources, and about from whom such costs should be recouped.

Overall, it would seem hard to make an argument that children do not have a fundamental right to justice in a matter as essential as the habitable condition of the planet on which they will live and raise their own children. Quite clearly, South Africans, especially health workers, have a collective responsibility to advance that right. Sadly, it may be necessary for youth in the country to use the courts to remind us of that.

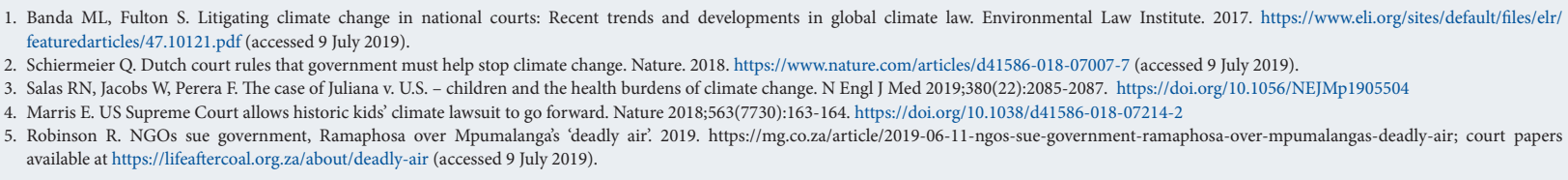

schools heightens transmission of infections. High temperatures and temperature variations also exacerbate asthma in adolescents, ${ }^{[17,18]}$ and these associations may be stronger than for other age groups. ${ }^{[19]}$ Dust and pollen increments from climate change, and air pollution in itself, also raise risks for asthma and allergies in adolescents. ${ }^{[20]}$ Importantly, heat raises exposure to environmental toxins, which is worrying as many schools in SA are located near areas with toxic substances, such as heavily trafficked roads, mine dumps and industrial operations.

The indirect effects of climate change also warrant mention. The biological and cognitive development of an adolescent occurs 


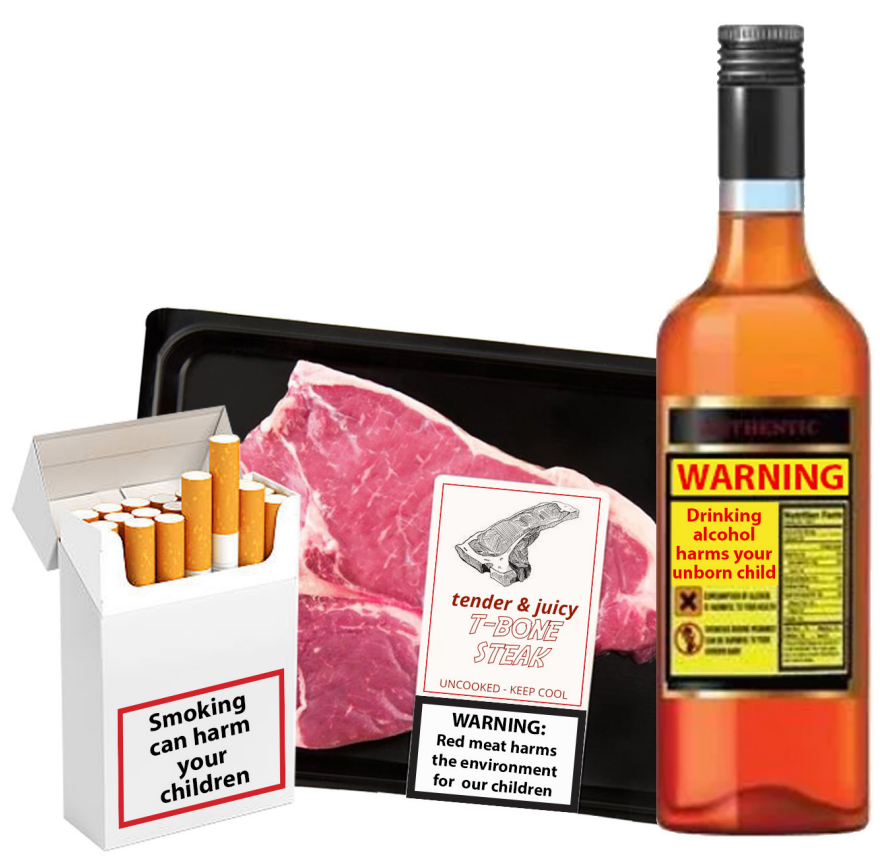

Fig. 2. Health and environment warnings on ruminant meat products could raise awareness of methane emissions and deforestation as consequences of cattle farming.

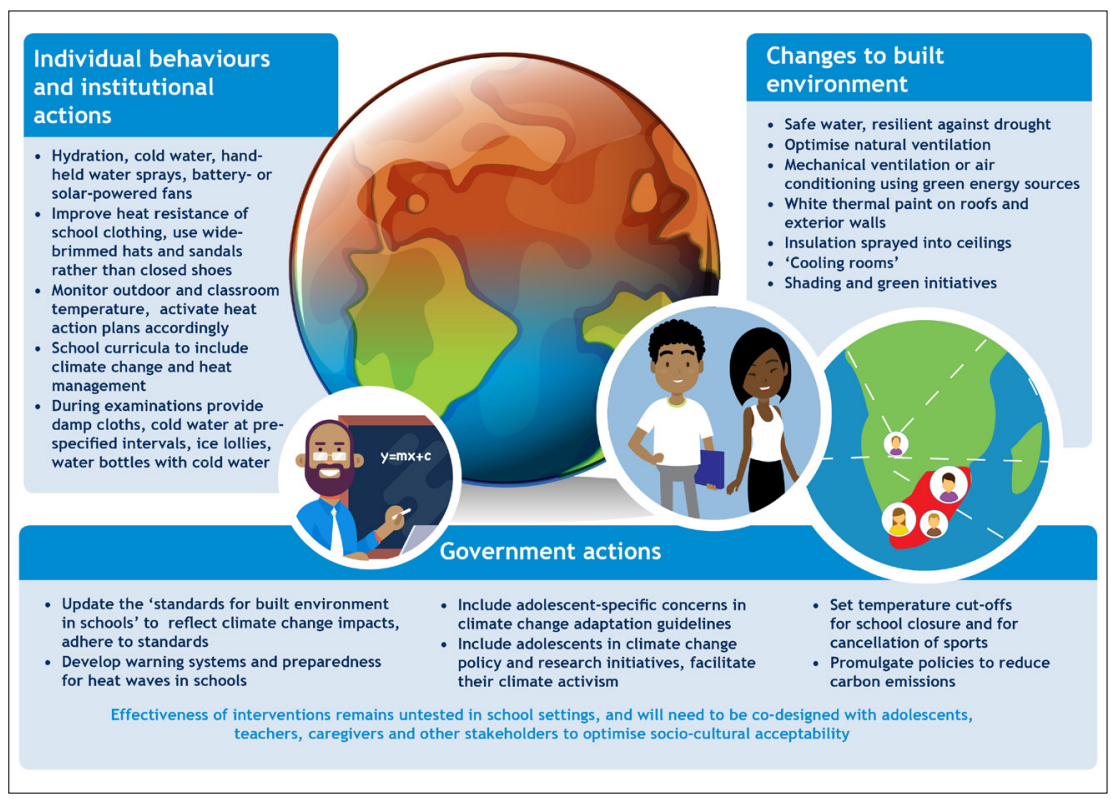

Fig. 3. Potential interventions to reduce the impact of climate change on adolescents at school.

in the context of their household, school and community: social disruptions, such as food insecurity, damage to infrastructure and migration, can therefore have a major impact on this age group.

Together, these direct and indirect impacts pose mental health risks for adolescents, including post-traumatic stress disorder, depression, anxiety, sleep disorders and even suicide. ${ }^{[21-23]}$ Heat exposure can also increase irritability, aggression and violence, ${ }^{[24]}$ a major concern given the rates of physical and sexual violence in schools in SA, both pupil-onpupil and between teacher and pupil. Extreme weather events such as storms, droughts and wildfires have been strongly linked with mental health conditions in adolescents, which commonly persist into adulthood. ${ }^{[25,26]}$ Recent figures from the United Nations show that globally there is at least one climate change disaster every week. ${ }^{[27]}$ Even if these disasters trigger mental health conditions in a small fraction of adolescents, that translates into a massive disease burden. ${ }^{[28]}$
The mental health and behavioural impacts of climate change are especially pronounced among adolescents who have pre-existing psychological vulnerabilities or resilience deficits. ${ }^{[29]}$ This is highly relevant in SA, where the burden of mental illness among adolescents is among the highest in the world. ${ }^{[30]}$ Early preventive interventions shortly after an extreme weather event, and involving adolescents themselves in disaster risk reduction and recovery, appear important in minimising the occurrence of mental health difficulties. ${ }^{[28]}$

\section{Heat exposure in schools: 'Sick building syndrome'}

While the Department of Basic Education mentions environmental factors such as ventilation and the hazards of non-brick structures in its school infrastructure standards, these have not yet been fully actualised ${ }^{[31]}$ In many schools, classrooms are made out of converted shipping containers or prefabricated sheeting with corrugated iron roofs. Most container classrooms have poor insulation, little natural ventilation and as many as 50 children in a class, who themselves generate a considerable heat load. ${ }^{[32]}$ In one study in Johannesburg, which has a relatively mild climate, temperatures reached as high as $47.5^{\circ} \mathrm{C}$ in the containers and the large majority of students reported experiencing heat-health symptoms every day, including drowsiness, poor concentration and thirst. ${ }^{[33]}$ These impacts will be even greater in hotter regions of the country, such as Northern Cape and Limpopo provinces. A study in Cameroon had similar findings, with notably higher symptoms among girls than boys. ${ }^{[34]}$ In both studies, the classroom windows and doors were often kept closed. Furthermore, many adolescents live in housing that is poorly resistant to heat. In informal settlements and some formal low-cost housing developments ('RDP' housing), for example, indoor temperature may be $4-5^{\circ} \mathrm{C}$ warmer than outdoors, conditions hardly conducive to completing homework, preparing for examinations and quality sleep. ${ }^{[35]}$

A large number of studies have documented the effects of temperature on educational performance, which is influenced not only by the temperature on the day of examinations, but by the total cumulative heat exposure over the academic year. ${ }^{[36,37]}$ In a meta-analysis involving 18 studies, the authors calculated that students in classrooms with an indoor temperature of $30^{\circ} \mathrm{C}$ scored $20 \%$ lower on tests than those in 
classes around $20^{\circ} \mathrm{C} .{ }^{[37]}$ The performance of adolescents appears to be more heat sensitive than the performance of adults in occupational settings. ${ }^{[38]}$ Nevertheless, teachers exposed to high temperatures may also become lethargic and irritable. ${ }^{[38]}$

There are major equity issues at stake here: adolescents who have attended well-resourced schools with temperatures carefully controlled for optimal concentration will compete for jobs or places at university alongside those who wrote school-leaving examinations in temperatures above $40^{\circ} \mathrm{C}$, and were drowsy and probably poorly hydrated. That these examinations are written in the summer months in SA further accentuates these concerns.

In classes with poor ventilation, levels of $\mathrm{CO}_{2}$ or stuffiness rise together with temperature, and children experience symptoms characteristic of the 'sick building syndrome. ${ }^{\text {[39] }}$ These symptoms affect concentration and student learning, and even school attendance and rates of asthma attacks. ${ }^{[40-46]}$ Window opening is a key means of removing heat and $\mathrm{CO}_{2}$. However, in towns and cities with high pollution levels, such as Witbank, one of the most polluted towns in the world, doing so would increase exposure to outdoor air pollution. Greenhouse gases and other pollutants in themselves have substantial health consequences and are increasingly viewed as 'secondary smoke' exposures for children, no less harmful or unkind than smoking cigarettes in an adolescent's bedroom.

\section{Interventions to reduce heat stress in schools}

The interventions proposed below are based on the premise that thermal comfort drives learning, reduces heat-related aggression, and improves comfort and wellbeing for scholars and teachers. These interventions require supportive policy frameworks and efforts by the departments of Health and Basic Education to mainstream climate change adaptation interventions and awareness-raising activities into schools.

Longer-term initiatives to make the built environment more heat resistant are clearly critical, especially replacing containers and prefabricated buildings with brick classrooms. Until that occurs, behavioural and institutional actions could be taken (Fig. 3) ${ }^{[47]}$ Few interventional studies have addressed this topic, however. In one study in Costa Rica, learning outcomes improved after air conditioning was installed in the classrooms. ${ }^{[48]}$ Studies in high-income countries have also shown that the effects of heat on exam performance can be ameliorated by air conditioning ${ }^{[36]}$ and mechanical ventilation. ${ }^{[49]}$ But further research is needed to identify effective interventions other than air conditioning. These could potentially include providing cold water at regular prespecified intervals, use of the ancient Egyptian method of applying damp cloths to the body, which cools as the water evaporates, and improved natural ventilation, which also lowers risks of tuberculosis transmission in schools. ${ }^{[0,51]}$ Schools could also consider substituting closed shoes with sandals, using light-coloured, loose clothing, and adapting school hours during the hottest seasons, with either earlier starting times or a longer lunchtime break and later finishing hours. Planting trees in school grounds provides shade and cooling, and other health and environmental benefits. A cooling room' could be developed in the school, where, for example, fans are installed on the walls, the roofs are painted white, plants are hung on the walls and trees are planted nearby. During extremely hot days pupils could spend time in the cooling room during breaks or after school, and the room could be used for examinations.

One possible study design could involve randomising pupils to write examinations in classes where some of these interventions have been applied and comparing them with pupils in existing classrooms without such interventions. Showing that a few interventions can alter educational outcomes could provide impetus for implementing and scaling up climate adaptation activities in schools.

Implementing these interventions may face challenges, however, as many people view heat only as a nuisance factor or a 'normal' occurrence to be tolerated, rather than as a modifiable risk factor that can influence health and learning. Ideally, interventions need to be co-designed with adolescents, teachers, caregivers and other stakeholders to enhance acceptability and buy-in. For example, while there may be advantages to holding classes outdoors under shading on hot days, outdoor classes have come to symbolise failed school infrastructure in SA, and may be viewed as such, rather than as a heat-reducing measure.

\section{Conclusions}

The quality of the school environment and experiences in this setting may set the scene for adolescents' health and wellbeing as adults, and for their capacity to achieve their full potential in life and to contribute to society and national economies. Climate change adaptation in schools may be an under-recognised but important strategy for countering inequities in SA. The pre-existing mental health vulnerabilities of adolescents and challenges in the education sector in SA mean that effects of climate change may threaten the already fragile resilience of adolescents in the country.

Further research is needed to identify which interventions can most effectively reduce the impacts of heat exposure at school, and ensure that fewer adolescents in SA have to contend with 'sick buildings' in their learning environment. As part of this, we need to gauge how much adolescents understand about climate change, cultivate their activism in this field, and document the impacts of heat exposure on learning, mental health and violence in schools.

In SA, adolescents stood up against apartheid. The country now needs its own brand of youth activism that stands up against environmental destruction. Safeguarding schools against the health and education impacts of heat, allied with increasing awareness of climate change, is a good place to start.

Acknowledgements. We thank Lois Harden, Faculty of Health Sciences, University of the Witwatersrand, for input on the physiology of thermoregulation in adolescents. Also thanks to Anita Kleinsmidt and Timothy Lloyd for review of the climate law text.

\section{F Chersich, ${ }^{1}$ F Scorgie, ${ }^{1}$ C Y Wright, ${ }^{2,3}$ S Mullick, ${ }^{1}$ A Mathee, ${ }^{3,4}$ J Hess, ${ }^{5}$ M Richter, ${ }^{6} \mathrm{H}_{\text {Rees }}{ }^{1}$}

\section{${ }^{1}$ Wits RHI (Wits Reproductive Health and HIV Institute), Faculty of Health Sciences, University of the Witwatersrand, Johannesburg, South Africa}

mchersich@wrhi.ac.za

${ }^{2}$ Department of Geography, Geoinformatics and Meteorology, Faculty of Natural and Agricultural Sciences, University of Pretoria, South Africa

${ }^{3}$ Environment and Health Research Unit, South African Medical

Research Council, Pretoria, South Africa

${ }^{4}$ Environmental Health Department, Faculty of Health Sciences, University of Johannesburg, South Africa

${ }^{5}$ Departments of Emergency Medicine, Environmental and Occupational Health Sciences, and Global Health, Center for Health and the Global Environment (CHanGE), Schools of Medicine and Public Health, University of Washington, USA

${ }^{6}$ Sonke Gender Justice, South Africa; School of Public Health and

Family Medicine, University of Cape Town, South Africa; and African Centre for Migration and Society, University of the Witwatersrand, Johannesburg, South Africa 
1. Campbell E, Skovdal M, Campbell C. Ethiopian students' relationship with their environment: Implications for environmental and climate adaptation programmes. Children's Geographies 2013;11(4):436-460. https://doi.org/10.1080/14733285.2013.812302

2. Stott R, Smith R, Williams R, Godlee F. Schoolchildren's activism is a lesson for health professionals BMJ 2019;365:11938. https://doi.org/10.1136/bmj.11938

3. Marris E. US Supreme Court allows historic kids' climate lawsuit to go forward. Nature 2018;563(7730):163-164. https://doi.org/10.1038/d41586-018-07214-2

4. Mugambiwa SS, Dzomonda O. Climate change and vulnerability discourse by students at a South African university. Jamba (Potchefstroom, South Africa) 2018;10(1):a476. https://doi.org/10.4102/ amba.v10i1.476

5. Sulistyawati S, Mulasari SA, Sukesi TW. Assessment of knowledge regarding climate change and health among adolescents in Yogyakarta, Indonesia. J Environ Public Health 2018;2018:9716831. https://doi. org/10.1155/2018/9716831

6. Hendricks A, Postman Z, Binda M. South African youths march for action against climate change. GroundUp. 2019. https://www.groundup.org.za/article/climate-strike/ (accessed 9 July 2019).

7. Statistics South Africa. Demographic profile of adolescents in South Africa. Report 03-00-10. Pretoria: Stats SA, 2018. http://www.statssa.gov.za/publications/Report\%2003-00-10/Report\%2003-00-102016. pdf (accessed 9 July 2019).

8. Ncontsa VN, Shumba V. The nature, causes and effects of school violence in South African high schools. S Afr J Educ 2013;33(3).

9. Marais P. 'We can't believe what we see': Overcrowded classrooms through the eyes of student teachers. S Afr J Educ 2016;36(2).

10. Cedeno Laurent JG, Williams A, Oulhote Y, Zanobetti A, Allen JG, Spengler JD. Reduced cognitive function during a heat wave among residents of non-air-conditioned buildings: An observational study of young adults in the summer of 2016. PLoS Med 2018;15(7):e1002605. https://doi.org/10.1371/
s. study of young adults in
journal.pmed.1002605

11. Sheffield PE, Landrigan PJ. Global climate change and children's health: Threats and strategies for prevention. Environ Health Perspect 2011;119(3):291-298. https://doi.org/10.1289/ehp.1002233

12. Falk B, Dotan R. Children's thermoregulation during exercise in the heat: A revisit. Appl Physiol Nutr Metab 2008;33(2):420-427. https://doi.org/10.1139/H07-185

13. Somboonwong J, Sanguanrungsirikul S, Pitayanon C. Heat illness schoolboys participating in physical education class in tropical climate: An analytical surveillance in prospective descriptive study. BMJ Open 2012;2(4). https://doi.org/10.1136/bmjopen-2011-000741

14. Atkinson HG, Bruce J. Adolescent girls, human rights and the expanding climate emergency. Ann Glob Health 2015;81(3):323-330. https://doi.org/10.1016/j.aogh.2015.08.003

15. Statistics South Africa. Survey of activities of young people, 2015. Statistical release P0212. Pretoria: Stats SA, 2017. http://www.statssa.gov.za/publications/P0212/P02122015.pdf (accessed 9 July 2019).

16. United Nations Children's Fund (UNICEF). WASH: Ensuring safe water, sanitation and hygien help children to survive and thrive. 2017. https://www.unicef.org/southafrica/SAF_brief_wash.pdf (accessed 9 July 2019).

17. Li K, Ni H, Yang Z, et al. Effects of temperature variation between neighbouring days on daily hospital visits for childhood asthma: A time-series analysis. Public Health 2016;136:133-140. https://doi. org/10.1016/j.puhe.2016.04.002

18. O'Lenick $\mathrm{CR}$, Winquist A, Chang $\mathrm{HH}$, et al. Evaluation of individual and area-level factors as modifiers of the association between warm-season temperature and pediatric asthma morbidity in Atlanta, GA. Environ Res 2017;156:132-144. https://doi.org/10.1016/j.envres.2017.03.021

19. Soneja S, Jiang C, Fisher J, Upperman CR, Mitchell C, Sapkota A. Exposure to extreme heat and precipitation events associated with increased risk of hospitalization for asthma in Maryland, U.S.A. precipitation events associated with increased risk of hospitalization
Environ Health 2016;15:57. https://doi.org/10.1186/s12940-016-0142-z

20. Zhang Y, Bielory L, Mi Z, Cai T, Robock A, Georgopoulos P. Allergenic pollen season variations in the Zhang $\mathrm{Y}$, Bielory $\mathrm{L}, \mathrm{Mi}$, Cai $\mathrm{T}$, Robock A, Georgopoulos P. Allergenic pollen season variations in the
past two decades under changing climate in the United States. Glob Chang Biol 2015;21(4):1581-1589. past two decades under changing
https://doi.org/10.1111/gcb.12755

21. Burke SEL, Sanson AV, van Hoorn J. The psychological effects of climate change on children. Curr Psychiatry Rep 2018;20(5):35. https://doi.org/10.1007/s11920-018-0896-9

22. Younan D, Li L, Tuvblad C, et al. Long-term ambient temperature and externalizing behaviors in adolescents. Am J Epidemiol 2018;187(9):1931-1941. https://doi.org/10.1093/aje/kwy104

23. Kim Y, Kim H, Honda Y, et al. Suicide and ambient temperature in East Asian countries: A timestratified case-crossover analysis. Environ Health Perspect 2016;124(1):75-80. https://doi.org/10.1289/ ehp. 1409392

24. Chersich MF, Swift CP, Edelstein I, et al. Violence in hot weather: Will climate change exacerbate rates of violence in South Africa? S Afr Med J 2019;109(7):447-449. https://doi.org/10.7196/SAMJ.2019. v109i7.14134

25. Dean JG, Stain HJ. Mental health impact for adolescents living with prolonged drought. Aust J Rural Health 2010;18(1):32-37. https://doi.org/10.1111/j.1440-1584.2009.01107.x

26. Austin EK, Handley T, Kiem AS, et al. Drought-related stress among farmers: Findings from the Australian Rural Mental Health Study. Med J Aust 2018;209(4):159-165. https://doi.org/10.5694/ mja17.01200

27. The Guardian. One climate crisis disaster happening every week, UN warns. 2018. https://www. theguardian.com/environment/2019/jul/07/one-climate-crisis-disaster-happening-every-week-unwarns (accessed 9 July 2019)

28. Dyregrov A, Yule W, Olff M. Children and natural disasters. Eur J Psychotraumatol 2018;9(Suppl 2):1500823. https://doi.org $/ 10.1080 / 20008198.2018 .1500823$

29. Majeed H, Lee J. The impact of climate change on youth depression and mental health. Lancet Planetary Health 2017;1(3):e94-e95. https://doi.org/10.1016/s2542-5196(17)30045-1
30. Cheng Y, Li X, Lou C, et al. The association between social support and mental health among vulnerable adolescents in five cities: Findings from the study of the well-being of adolescents in vulnerable environments. J Adolesc Health 2014;55(6 Suppl):S31-S38. https://doi.org/10.1016/j. vulnerable environmealth.2014.08.020

31. South Africa. South African Schools Act, 1996 (Act No. 84 of 1996): Regulations relating to minimum uniform norms and standards for public school infrastructure. Government Gazette No. 37081, 2013. 2. Ntongana T. 'We are 52 students in one container'. GroundUp. 2018. https://www.groundup.org.za/ article/philippi-high-school-learners-march-parliament/ (accessed 9 July 2019).

33. Bidassey-Manilal S, Wright CY, Engelbrecht JC, Albers PN, Garland RM, Matooane M. Students' perceived heat-health symptoms increased with warmer classroom temperatures. Int J Environ Res Public Health 2016;13(6):566. https://doi.org/10.3390/ijerph13060566

34. Dapi LN, Rocklov J, Nguefack-Tsague G, Tetanye E, Kjellstrom T. Heat impact on schoolchildren in Cameroon, Africa: Potential health threat from climate change. Global Health Action 2010;3:1. https:/ doi.org/10.3402/gha.v3i0.5610

35. Naicker $\mathrm{N}$, Teare J, Balakrishna $\mathrm{Y}$, Wright $\mathrm{CY}$, Mathee A. Indoor temperatures in low cost housin in Johannesburg, South Africa. Int J Environ Res Public Health 2017;14(11):1310. https://doi org/10.3390/ijerph14111410

6. Goodman J, Hurwitz M, Park J, Smith J. Heat and learning. HKS Working Paper No. RWP18-014. 2018. https://doi.org/10.2139/ssrn.3180724 (accessed 9 July 2019).

37. Wargocki P, Porras-Salazar JA, Contreras-Espinoza S. The relationship between classroom temperature and children's performance in school. Build Environ 2019;157(15):197-205. https://doi.org/10.1016/j. buildenv.2019.04.046

38. International Labour Organization. Working on a warmer planet: The impact of heat stress on labour productivity and decent work. 2019. https://www.ilo.org/wcmsp5/groups/public/---dgreports/-dcomm/---publ/documents/publication/wcms_711919.pdf (accessed 9 July 2019).

39. United States Environmental Protection Agency. Indoor Air Facts No. 4 (revised): Sick building syndrome. 1991. https://www.epa.gov/sites/production/files/2014-08/documents/sick_building factsheet.pdf (accessed 9 July 2019)

40. Wargocki P, Wyon DP. The effects of outdoor air supply rate and supply air filter condition in classrooms on the performance of schoolwork by children. HVAC\&R Res 2007;13(2):165-191. https: $/$ doi.org/10.1080/10789669.2007.10390950

41. Haverinen-Shaughnessy U, Shaughnessy RJ. Effects of classroom ventilation rate and temperature on students' test scores. PloS One 2015;10(8):e0136165. https://doi.org/10.1371/journal.pone.0136165

42. Twardella D, Matzen W, Lahrz T, et al. Effect of classroom air quality on students' concentration: Twardella D, Matzen W, Lahrz T, et al. Effect of classroom air quality on students concentration:
Results of a cluster-randomized cross-over experimental study. Indoor Air 2012;22(5):378-387. https:/ doi.org/10.1111/j.1600-0668.2012.00774.x

43. Mendell MJ, Eliseeva EA, Davies MM, Lobscheid A. Do classroom ventilation rates in California elementary schools influence standardized test scores? Results from a prospective study. Indoor Ai 2016;26(4):546-557. https://doi.org/10.1111/ina.12241

44. Gaihre S, Semple S, Miller J, Fielding S, Turner S. Classroom carbon dioxide concentration, schoo attendance, and educational attainment. J School Health 2014;84(9):569-574. https://doi.org/10.1111/ josh. 12183

45. Shendell DG, Prill R, Fisk WJ, Apte MG, Blake D, Faulkner D. Associations between classroom CO concentrations and student attendance in Washington and Idaho. Indoor Air 2004;14(5):333-341. https://doi.org/10.1111/j.1600-0668.2004.00251.x

46. Mi YH, Norback D, Tao J, Mi YL, Ferm M. Current asthma and respiratory symptoms among pupils in Shanghai, China: Influence of building ventilation, nitrogen dioxide, ozone, and formaldehyde in classrooms. Indoor Air 2006;16(6):454-464. https://doi.org/10.1111/j.1600-0668.2006.00439.x

47. Hyndman B. 'Heat-smart' schools during physical education (PE) activities: Developing a policy to protect students from extreme heat. Learning Communities: International Journal of Learning i Social Contexts (Special Issue: 2017 30th ACHPER International Conference), 21, 56-72. 2017. https:/ doi.org/10.18793/lcj2017.21.06

48. Porras-Salazar JA, Wyon DP, Piderit-Moreno B, Contreras-Espinoza S, Wargocki P. Reducing classroom temperature in a tropical climate improved the thermal comfort and the performance of elementary school pupils. Indoor Air 2018;28(6):892-904. https://doi.org/10.1111/ina.12501

49. Petersen S, Jensen KL, Pedersen AL, Rasmussen HS. The effect of increased classroom ventilation rate Petersen $\mathrm{S}$, Jensen $\mathrm{KL}$, Pedersen $\mathrm{AL}$, Rasmussen $\mathrm{HS}$. The effect of increased classroom ventilation rate
indicated by reduced $\mathrm{CO}_{2}$ concentration on the performance of schoolwork by children. Indoor Air 2016;26(3):366-379. https://doi.org/10.1111/ina.12210

50. Public Health England. Looking after children and those in early years settings during heatwaves Guidance for teachers and professionals. 2015. https://assets.publishing.service.gov.uk/government/ uploads/system/uploads/attachment_data/file/428850/Looking_After_Children_Heat_PHE_AC AB_Publications_MP_JRM_FINAL.PDF (accessed 9 July 2019).

51. Richardson ET, Morrow CD, Kalil DB, Ginsberg S, Bekker LG, Wood R. Shared air: A renewed focus on ventilation for the prevention of tuberculosis transmission. PloS One 2014;9(5):e96334. https://doi org/10.1371/journal.pone.0096334

S Afr Med J 2019;109(9):615-619. https://doi.org/10.7196/SAMJ.2019.v109i9.14327 